\title{
ASYMMETRIC PASS-THROUGH EFFECTS OF OIL PRICE ON ECONOMIC GROWTH IN MALAYSIA
}

\author{
Umar Bala \\ Universiti Putra Malaysia, Bauchi State University, Gadau \\ Chin Lee* \\ Universiti Putra Malaysia \\ Rabiu Maijama'a \\ Nigerian National Petroleum Corporation Retail Ltd
}

\begin{abstract}
S
This empirical analysis intends to examine the asymmetric response of economic growth when the oil price changes in Malaysia by applying threshold autoregressive (TAR) and momentum threshold autoregressive (MTAR) cointegration and asymmetric adjustment models. The results revealed that the oil price has an asymmetric impact on Malaysian economic growth. We found that when oil price increases this accelerates economic growth; however, the speeds of adjustment back to the steady position were insignificant. When the oil price dropped, oil price significantly and negatively affects economic growth for a period of time and then returns back to its normal position. The results revealed that Malaysian economic growth constantly benefits when the oil price increases and is temporarily negatively affected when oil prices drop. The results have important policy implications. This suggests that it is essential to the policy makers to consider different policy responses for hikes and drops in oil prices. The result implies that negative oil price shock would lower economic growth, however it is temporary. Therefore, policy makers might response by implementing expansionary monetary policy to stimulate economic growth. The explanation is intuitive. For example, an increase in the money supply would normally pull down the interest rate which would further encourage consumption and investment, stimulate economic growth, which would increase oil demand and push up its price.
\end{abstract}

Keywords: Asymmetric, Pass-Through, Oil Price, Economic Growth.

Received: 25 September 2019

Accepted: 10 May 2021

https://doi.org/10.33736/ijbs.3755.2021

\section{INTRODUCTION}

The impact of crude oil price on economic growth has drawn much attention from researchers. First oil price shock occurred during the year 1973, due to the OPEC embargo (Kriskkumar \& Naseem, 2019). As a result, the crude oil price fluctuating about $\$ 12$ to $\$ 14$ per barrel. During the Iran-Iraq war and the Iranian revolution, from 1979 to 1980 the crude oil production was cut down by 10 percent, which resulting the oil price increase from $\$ 14$ to $\$ 35$ per barrel (Rafiq et al., 2009).

\footnotetext{
- Corresponding author: School of Business and Economics, Universiti Putra Malaysia, 43300 UPM, Serdang, Selangor Darul Ehsan, Malaysia; Tel: +60-603-9769-7769; E-mail: leechin@upm.edu.my
} 
The increasing oil price has forced the leading customers and firms to implement an economical product and led them to enlarge the search and increase the production of non-OPEC members. In early 1982 to 1985 , OPEC made an effort to stabilize the price of crude oil through production quota but, this major protection, global economic meltdown and illegal quota produced by OPEC member countries have contributed to $\$ 10$ drop in crude oil price per barrel (Baffes et al., 2015). Then, the oil price had been steadily increased for three decades, except for 2008 to 2009 where oil price has declined during the subprime crisis.

For the past decades, energy markets acknowledge persistent increases in the prices of energy products, while in mid-2014 oil prices drastically dropped. These unexpected changes affected world economic growth, especially in oil-producing and oil-exporting countries, including Malaysia. There is a lack of research in previous studies into investigating how an economy will adjust after oil price changes, especially in developing economies. The Malaysian economy is an emerging one, which is vibrant and open, and largely driven by rich resources, energy and commodities for its industrial development. Malaysia is notable as an oil exporter, being among the top 10 liquefied natural gas (LNG) producers in the world. The nature of the Malaysian economy gives motivation to undertake this study (Ahmed \& Wadud, 2011). Increases and decreases in petrol prices affect Malaysian productivity and changes in the level of productivity may impact on economic growth. Several previous studies have shown evidence that an increase in petrol prices can harm economic growth (Noordin, 2009).

Malaysia, as an oil and gas exporter, has benefited from previous increases in energy prices. In Figure 1 this can be observed from the trends in the relationship of changes of oil prices and the response in Malaysian Gross Domestic Product (GDP), within the period of our study, namely 1975 to 2018. The Malaysian GDP continued to grow during the sample period with the increases in oil price, the only interruptions occurring when oil prices dropped. Most of the negative changes within a year disappeared and the GDP moved back to the normal pattern. We managed to identify five major negative responses of GDP when oil prices dropped: from 1985 to 1986, 1997 to 1998 , 2000 to 2001,2008 to 2009 and 2014 to 2015. In 1978, 1988 and 1994, the GDP didn't respond to the negative changes in oil price. This motivates us to empirically study whether Malaysian economic growth responds differently during oil price hikes and oil price drops. Overall, this study will find out whether economic growth is sensitive to oil price changes and whether the adjustments back to normal position is asymmetrical. The findings of this study will have significant implications to the policy makers in response to different oil price changes. This is particular important for allowing the monetary authority to make and modify suitable monetary policies to stimulate economic growth or depress inflation pressure. In addition, the findings also enable traders to forecast economic performance and formulate their investment strategy. 
Figure 1: Oil Price (OP) and Malaysian GDP

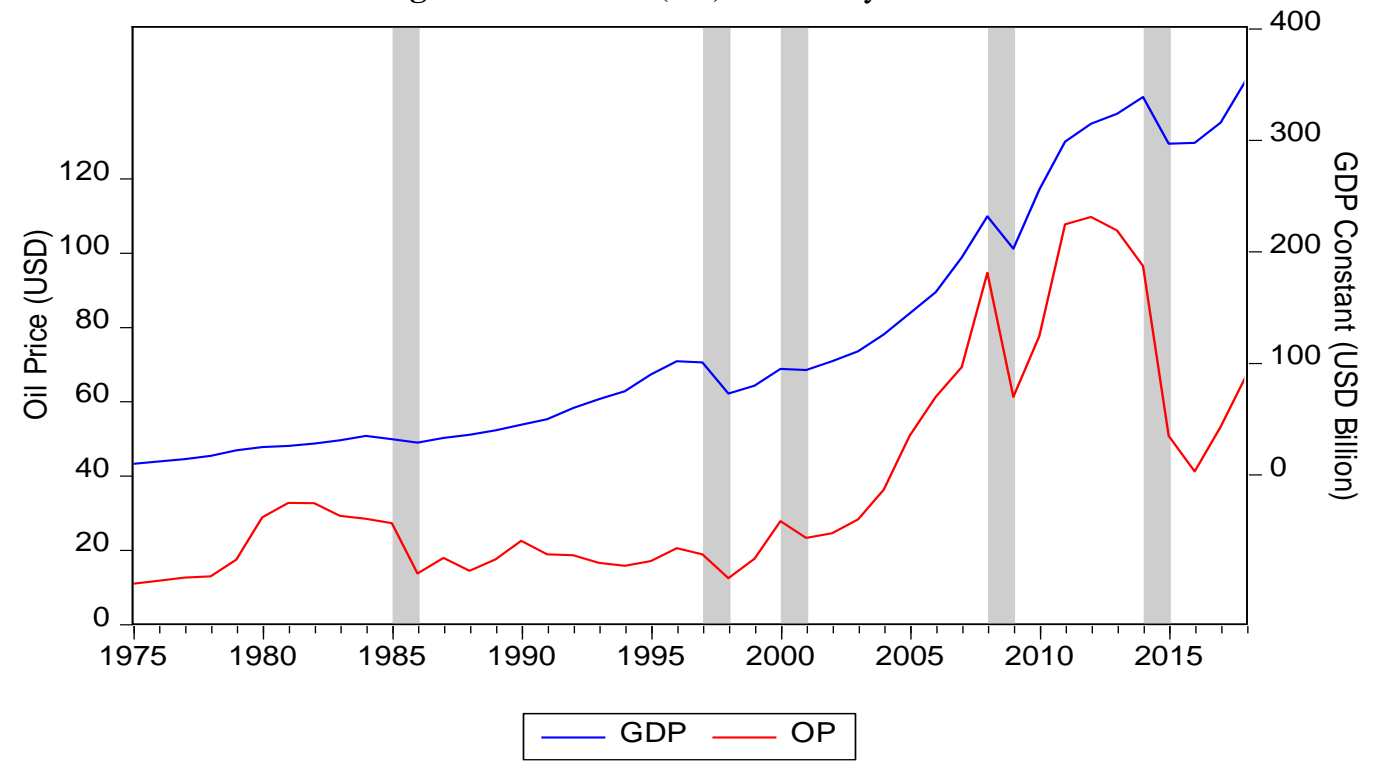

This paper will extend the existing literature in at least three ways. First, most published studies related to Malaysia have failed to examine the asymmetric relationship of oil prices on economic growth ${ }^{1}$. In fact, a structural change in oil price persistence may occur as oil markets encounter obvious adjustments in economic environment and public policy. Events such as Dot-Com Bubble Crash in 2000 and the Subprime Crisis in 2007 have likely made oil price fluctuations a nonlinear dynamic process and the persistence effects of oil price fluctuations to economic growth (Liu et al., 2015). Second, two previous studies claimed to study the asymmetric relationship of oil prices on economic activities in ASEAN-5 including Malaysia; however, these studies, by Ahmed and Wadud (2011), only applied SVAR, and Izraf et al. (2015) employed a panel VAR method. Instead, this study used Threshold cointegration (TAR and MTAR) to find the asymmetric response of economic growth when oil prices changed. Third, the oil price proxy used in this study is more appropriate. There are several categories of crude oil in the world; the type that Malaysia exports is Miri. Therefore, it is more appropriate to use the Miri oil price to study the effect of oil prices in Malaysia. Ahmed and Wadud (2011) used the Hamilton index for net oil price increase, while Izraf et al., (2015) used the Dubai crude oil price to study the effect of oil prices in ASEAN-5, including Malaysia.

The current paper is organized as follows: Section 2 focuses on the literature review regarding the relationship between oil price and macroeconomics variables. A discussion on the model and data is presented in Section 3. Next, discussion of the results is provided in Section 4. Finally, concluding remarks and policy implications are presented in Section 5.

\footnotetext{
${ }^{1}$ To name a few, (Razmi et al., 2016; Liew \& Balasubramaniam, 2017; Wong \& Shamsudin, 2017; Xuan et al., 2018).
} 


\section{LITERATURE REVIEW}

A range of empirical literature has conducted studies into the impact of fluctuations of oil prices and the macroeconomics response. However, these studies assumed a symmetric adjustment between the variables. The recent studies suggest the possibility of an asymmetric relationship among the variables (Chen et al., 2013). This means the positive and negative shock may not affect macroeconomic variables in the appropriate manner or it is always not a proportional response to the positive or negative shock (Wan \& Lee, 2001; Hooker, 2002; Aizenman \& Pinto, 2004; Olomola \& Adejumo, 2006; Aliyu, 2009; Madueme \& Nwosu, 2010; Aguiar-Conraria \& Soares, 2011; Alley et al., 2014; Ekong \& Effiong, 2015). Such a contention of an asymmetric relationship between the variables may be plausible, for a variety of reasons, of which on the forefront of these reasons, is that a number of empirical studies have found that economic growth, at least, evolves as a nonlinear process over the business cycle (see Beechey \& Osterholm, 2008; Shelly \& Wallace, 2011 for examples). Chang et al. (2010) studied four countries, namely: India, Brazil, China and Russia, and the authors found asymmetric cointegration and the nominal exchange rate plays a significant role in absorbing the long-run fluctuation. Chang et al. (2011) investigated 22 African countries, applying monthly data ranging from 1980:1 to 2003:12. They found that the adjustment mechanism is asymmetric in most of these African countries. Ahmad and Aworinde (2016) found that there is different form of adjustment when the exchange rate changes. Appreciation is faster (when disequilibrium occurred) than depreciation in most of the countries.

Numerous studies have been conducted to investigate and compare the asymmetrical of oil price shocks on economic growth across countries and mixed results were obtained. Rahman and Serletis (2010) studied nonlinearity in oil prices using monthly data from the USA, ranging from 1983:M1 to 2008:M12. A nonlinear VAR approach was applied and found that the intervention of monetary policy not only stabilises the effects of oil price shocks, but it also contributes to the asymmetric output response. Fattouh (2010) used weekly data ranging from 1997:1:W1 to 2008:12:W4 to investigate the threshold point in oil price changes applying a threshold AR model. This study reveals robust confirmation of threshold properties in the adjustment process toward the equilibrium. Bala and Chin (2018) used nonlinear ARDL to find the asymmetric behaviour of oil prices on inflation. The results indicate that both increases and decreases in oil prices influence inflation positively, and the effect is more pronounced when the oil price dropped. Furthermore, increases in food production reduced inflation. Nazlioglu (2011) investigated the impact of oil prices on agricultural prices using U.S. weekly data ranging from 1994:W1 to 2010:W4. The results reveal evidence of non-linear reactions of agricultural prices when oil prices change. Chang et al. (2011) used monthly data samples from a period from 1980:M1 to 2003:M12 to investigate the asymmetric speed of adjustment when oil prices change in 22 African countries. They found that there is an asymmetric adjustment toward equilibrium in the long run.

Pal and Mitra (2015) confirmed the existence of nonlinear effects. The significant asymmetric effect was at the lower quartiles of an oil price shock in the U.S. economy. Jammazi et al. (2015) found that in 18 major currencies there is a significant short and long-run asymmetric pass-through of exchange rates to oil prices. Ibrahim and Chancharoenchai (2014) discovered a sign of asymmetric adjustments of the aggregate and disaggregates consumer price in Thailand when the oil price changes. The asymmetric adjustment was verified by Mork et al. (1994), who examined the data of industrialized nations, and found that there was a negative and significant relationship between the increase in oil prices and output, while the fall of oil prices was found to be statistically 
insignificant. Lee et al. (1995), using the generalized autoregressive conditional heteroscedastic (GARCH) model, examined the impacts of positive and negative changes of oil prices on economic activities. The results show asymmetric adjustment, and the authors concluded that positive oil price shocks have a significant impact on economic activities, while negative oil price shocks are statistically insignificant, which means there is no impact.

In the context of Malaysia, a few studies had examined the impact of oil price shocks on economic growth. However, these studies focus on the long-run perspective and rather less study emphasize on the non-linearity perspective. For example, Ahmed and Wadud (2011) investigated the effects of oil price shocks on real economic activities in ASEAN-5, including Malaysia, using the SVAR method. The results indicate that there is a long dampening effect of oil price volatility shock on Malaysian industrial production. Similarly, Izraf et al. (2015) used a panel VAR model to examine the effect of oil prices on the economic activity in ASEAN-5. The authors also found that the response of GDP to the price of oil was negative. However, the above studies used the standard model of cointegration tests that assume a linear relationship and a symmetric adjustment in cointegrated variables. This might lead to a misspecification if, in actual fact, the variables exhibit an asymmetric relationship ${ }^{2}$. Therefore, the threshold autoregressive (TAR) and momentum threshold autoregressive (MTAR) models introduced by Enders and Siklos (2001) to estimate the asymmetrical cointegrating relationship are more appropriate.

\section{METHODOLOGY}

This study adopts a model of the long-run relationship between oil prices and Malaysia's economic activity by (Jbir \& Zouari-Ghorbel, 2009) and (Xuan \& Chin, 2015)

$$
Y=f(\text { reer }, p, \text { oil })
$$

Where: $l Y$ is the log form for industrial production index which is the proxy for economic activity, lreer indicates the log form for real effective exchange rate, lp represents the log form for consumer price index and loil is the log form for oil price based on WTI oil price.

Based on the objective to examine the asymmetric impacts of oil price changes on economic growth we used:

$$
G D P_{t}=\alpha_{0}+\beta_{1} \text { reer }_{t}+\beta_{2} c p i_{t}+\beta_{3} \operatorname{lop}_{t}+\mu_{t}
$$

Where: $l G D P_{t}$ is the $\log$ of GDP, lreer $_{t}$ is the log of real effective exchange rate, $l c p i_{t}$ is the log of consumer price index, $l o p_{t}$ is the log of oil price while $\mu_{t}$ is the error term.

A number of tests are necessary to examine the properties of the data before analysis of the dynamic model can be accepted. The first step is to examine the stationarity of the data or the integration of the data by using the well-known augmented Dickey-Fuller (ADF) and Phillips-Perron (PP) unit root tests. Next, the test of asymmetric cointegration developed by Enders and Siklos was applied.

\footnotetext{
${ }^{2}$ Please refer to Puah et al. (2017) for more detail.
} 
This has been tested in various research related to oil prices (Ibrahim \& Chancharoenchai, 2013; Ahmad \& Hernandez, 2013; Aliyu \& Tijjani, 2015). The advantage of applying the Enders and Siklos (2001) Threshold is that the TAR model can capture a deep cycle process if, for example, the variation above the threshold level is more prolonged than below the threshold level, while MTAR is capable of capturing sharp sequential movement, especially valuable when the series exhibits more momentum in one direction than the other direction (Bala et al., 2017). The threshold value can be zero or non-zero: if it is non-zero, it can be estimated using Chan's (1993) method of searching all possible thresholds, and the threshold is based on the lower residual sum of squares (RSS).

Prior to a cointegration test, this study will estimate the long-run equation using Ordinary Least Squares (OLS) method. From the estimated OLS regression, residuals will be extracted and tested for stationarity. For the three variables to be cointegrated, the residuals must be stationary at level. The estimation of residuals is estimates of $\rho_{1}$ and $\rho_{2}$ as shown in the following regressions:

$$
\Delta \mu_{t}=I_{t} \rho_{1} \mu_{t-1}+\left(1-I_{t}\right) \rho_{2} \mu_{t-1}+\varepsilon_{t},
$$

Where $\varepsilon_{t}$ is a white-noise disturbance; the residuals $\mu_{t}$, in Equation (2) are extracted to Equation (6) for further estimation; and $I_{t}$ is the Heaviside indicator function such that:

$$
\begin{aligned}
I_{t} & =\left\{\begin{array}{ll}
1 & \text { if } \mu_{t-1} \geq \tau \\
0 & \text { if } \mu_{t-1}<\tau
\end{array}\right. \text { TAR model, } \\
M_{t} & =\left\{\begin{array}{ll}
1 & \text { if } \Delta \mu_{t-1} \geq \tau \\
0 & \text { if } \Delta \mu_{t-1}<\tau
\end{array}\right. \text { MTAR model }
\end{aligned}
$$

Where: $\tau$ is the threshold value

The test equation will be:

$$
\Delta \mu_{t}=I_{t} \rho_{1} \mu_{t-1}+\left(1-I_{t}\right) \rho_{2} \mu_{t-1}+\sum_{i-1}^{\rho-1} \cdot \gamma_{t} \Delta \mu_{t-1}+\varepsilon_{t}
$$

The TAR model captures deviation from the equilibrium in the level or long-run while MTAR signifies an accumulation of change in the deviation. If $\mu_{t-1}$ is above the threshold, the adjustment coefficient is $\rho_{1} \mu_{t-1}$, and if $\mu_{t-1}$ is below the threshold, the adjustment coefficient is $\rho_{2} \mu_{t-1}$.

$$
\Delta \mu_{t}=I_{t} \rho_{1} \mu_{t-1}+\left(1-I_{t}\right) \rho_{2} \mu_{t-1}+\sum_{i-1}^{\rho-1} \cdot \gamma_{t} \Delta \mu_{t-1}+\varepsilon_{t}
$$

The TAR model captures deviation from the equilibrium in the level or long run while MTAR signifies an accumulation of change in the deviation. If $\mu_{t-1}$ is above the threshold, the adjustment coefficient is $\rho_{1} \mu_{t-1}$, and if $\mu_{t-1}$ is below the threshold, the adjustment coefficient is $\rho_{2} \mu_{t-1}$. The null hypothesis of no cointegration and symmetric shown below will be tested:

1. $\rho_{1}=\rho_{2}=0$, F-statistics

2. $\rho_{1}=\rho_{2}$, F-equal 
If Hypothesis 1 and 2 are rejected, we can conclude that there is a long-run cointegration relationship among the variables and the error correction term is asymmetric. The F-statistics refers to individual asymmetric cointegration and the F-equal represent the asymmetric relationship of both, the two tests must be significant.

The study employed annual statistical secondary data on RGDP per capita, real effective exchange rates $(2010=100)$, consumer price index $(2010=100)$ and Malaysian oil prices (Miri). All the data were obtained from the websites of the World Bank database except for the Malaysian oil prices (Miri), which were taken from OPEC Annual Statistical Bulletin, 2015. Based on the availability of the data, the data we utilized in this study were between the periods of 1975 to 2015 . All variables are expressed in natural logarithm.

\section{RESULTS AND DISCUSSION}

We conducted the two prominent unit root tests using Augmented Dickey-Fuller (ADF) and Phillips-Perron (PP) to test for stationarity. The evidence of the unit root test shows that gross domestic products (GDP), real effective exchange rate, consumer price index (CPI) and oil prices were stationary at the first difference that is appropriate to conduct the estimation. The validation of the order of integration suggests the need to conduct the Enders and Siklos Asymmetric cointegration tests.

Table 1: ADF and PP unit root tests

\begin{tabular}{cllllllll}
\hline \hline \multicolumn{3}{c}{ Level } & \multicolumn{7}{c}{ First-difference } & ADF & \multicolumn{3}{l}{ PP } & \\
\hline & ADF & & PP & & ADF & \\
\hline Variable & Constant & \& trend & Constant & \& trend & Constant & \& trend & Constant & \& trend \\
\hline lGDP & -1.7449 & -2.7828 & -1.6700 & -2.7828 & $-4.7589 \mathrm{a}$ & $-4.8491 \mathrm{a}$ & $-4.6736 \mathrm{a}$ & $-4.7778 \mathrm{a}$ \\
lreer & -1.3972 & -1.8847 & -1.4128 & -2.1116 & $-4.8839 \mathrm{a}$ & $-4.7890 \mathrm{a}$ & $-4.7228 \mathrm{a}$ & $-4.5789 \mathrm{a}$ \\
lcpi & -2.3200 & -1.9089 & -2.2681 & -2.0428 & $-3.4281 \mathrm{~b}$ & $-3.9368 \mathrm{~b}$ & $-3.5271 \mathrm{~b}$ & $-4.0358 \mathrm{~b}$ \\
lop & -1.4786 & -1.8174 & -1.5039 & -1.9073 & $-5.4847 \mathrm{a}$ & $-5.3929 \mathrm{a}$ & $-5.4848 \mathrm{a}$ & $-5.3934 \mathrm{a}$ \\
\hline \hline
\end{tabular}

Notes: \& trend is constant with trend; SIC is used to select the optimum lag order in ADF and PP test; and a and b denote significance level at 1 percent and 5 percent.

Table 2 presents the asymmetric test for cointegration which was conducted using TAR, TARconsistent, MTAR and M-TAR-consistent, and the results showed asymmetric cointegration. Hence, the null stated that the adjustments are symmetric $H_{0}: p_{1}=p_{0}$ against the alternative of asymmetric adjustment in the process of turning back to normal equilibrium. The tests were performed and we observed the standard F-statistics against the tabulated at 5 percent significant level.

TAR and MTAR test is required to validate the presence of asymmetric cointegration as against the traditional symmetric test by Engel-Granger and Johansen-Juselius. The results of the asymmetric test were conducted. The regression reveals that there are two lagged changes in residuals. Besides that, the Monte Carlo experiment had succeeded in searching for the critical value at $5 \%$ level of significance. Note that in the TAR model using the threshold value $\tau=0$, the value of F-statistics 0.1826 which is smaller than 1.8168 tabulated values at 5 percent critical value. 
Therefore, we conclude that cointegration does not exist. Subsequently, we used Chan's technique (1993) to search for the unknown threshold value. The threshold value found by Chan in TARconsistent was found to be 0.1302 . Hence, we found that cointegration still is not found, as the value of F-statistics 0.7438 is less than 5.1284 at 5 per cent critical value.

We further estimated the MTAR model with threshold value $\tau=0$, and we found the value of Fstatistics 12.0595 is greater than 3.7105 tabulated values at 5 percent significant level. Thus we reject the null hypothesis which states that cointegration does not exist. Furthermore, using MTAR consistent with a threshold search by Chan's techniques, we found a threshold value of -1.0504 at F-statistic 17.6796, which is higher than the 8.0263 critical values at 5 per cent provided by Monte Carlo. This allows us to conclude that the variables are cointegrated in MTAR zero and non-zero threshold. These two instances of evidence of cointegration permit us to continue investigating the nature of cointegration adjustment, whether symmetric or asymmetric. Considering the F-equal statistics in MTAR and MTAR-consistent are higher than the critical value provided by Monte Carlo at 5 per cent level of significance, we found that the oil price changes in the same proportion have different effects on economic growth, and the speed of adjustment may not necessarily be equal.

Table 2: TAR and MTAR cointegration and asymmetric tests

\begin{tabular}{lllll}
\hline \hline & TAR & TAR consistent & M-TAR & M-TAR consistent \\
\hline$\rho_{1}^{a}$ & $-0.3333(0.1351)$ & $-0.3744(0.1405)$ & $-0.1355(0.1089)$ & $-0.1565(0.0986)$ \\
$\rho_{2}^{a}$ & $-0.2512(0.1642)$ & $-0.2107(0.1545)$ & $-0.7430(0.1602)$ & $-0.9352(0.1766)$ \\
$\gamma_{1}^{a}$ & $0.4640(0.1540)$ & $0.4531(0.1535)$ & $0.5319(0.1338)$ & $0.5877(0.1283)$ \\
$\gamma_{2}^{a}$ & $-0.0583(0.1706)$ & $-0.0677(0.1690)$ & $0.0567(0.1485)$ & $-0.0109(0.1375)$ \\
Lags & 2 & 2 & 2 & 2 \\
$\tau$ & 0 & 0.1302 & 0 & -0.0504 \\
F-statistics & 0.1826 & 1.7438 & $12.0595^{\mathrm{b}}$ & $17.6796^{\mathrm{b}}$ \\
F-equal & 3.6291 & 3.9677 & $10.7968^{\mathrm{b}}$ & $14.1884^{\mathrm{b}}$ \\
\hline \hline
\end{tabular}

Notes: $\rho_{1}^{a}$ and $\rho_{2}^{a}$ are above and below threshold, $\gamma_{1}^{a}$ and $\gamma_{2}^{a}$ are F-equal hypothesis: $\rho_{1}=\rho_{2}$, F-statistics hypothesis $\rho_{1}=$ $\rho_{2}=0$. The optimal lags are determined based on AIC, b denote significance at $5 \%$ level.

To obtain the coefficients for the long-run cointegration model, the Dynamic Ordinary Least Squares (DOLS) estimation was done. The equation obtained is presented below. The result revealed the long-run coefficient of EXR is negative and significant at 1 percent level of significance, while for IPI, it is positive and also significant at 1 per cent.

$$
\begin{aligned}
& G D P_{t}=13.3254+0.0778 \text { reer }_{t}+2.5170 \text { cpi }_{t}+0.2092 o p_{t} \\
& \begin{array}{lll}
(0.0000) & (0.7720) & (0.0000)
\end{array} \\
& R^{2}=0.9822 \\
& P-\text { value }=0.0000
\end{aligned}
$$

\section{Asymmetric Error-correction Modelling}

The asymmetric error correction adjustment is estimated based on the momentum threshold value in MTAR and MTAR-consistent. In selecting the number of lags length to be used, we apply the most common approach for testing, starting from the general to the specific. This is to acquire the 
optimal and efficient results of asymmetric error correction adjustment.

Table 3 shows the asymmetric error correction results. The results revealed that the oil price has an asymmetric impact on Malaysian economic growth. We found that when oil price changes occurred, increases in oil prices accelerate the rate of economic growth and the speed of adjustment suggested by MTAR and MTAR-consistent models are 0.36 percent and 2.27 percent, however there are statistically insignificant. Meanwhile, when oil prices drop, it significantly and negatively affects economic growth. The speed of adjustment suggested by MTAR and MTAR-consistent models are 43.86 percent and 48.46 percent respectively at 5 percent significance level. This finding is consistent with the real practical situation in Malaysia. When the oil price increases, it affects economic growth positively, however, when the oil price drops, it will affect economic growth negatively and it also returns back to normal equilibrium. Our findings are contradict to the work of Izraf et al. (2015) and Kriskkumar and Naseem (2019). This is not surprising as different approach had been used in these studies. As for the study of Izraf et al. (2015), the study used a panel VAR model for the ASEAN-5 countries consisting of Indonesia, Malaysia, Philippines, Singapore and Thailand. Overall the results suggest that asymmetric effect for the case of ASEAN5. However, the response of GDP to oil price was found to be negative. Applied the method of NARDL, Kriskkumar and Naseem (2019) examined the effect of asymmetric oil price on economic growth of ASEAN oil exporters, namely Brunei, Malaysia and Vietnam. However, the study found that the effect of asymmetric oil price is insignificant for the case of Malaysia.

Table 3: Asymmetric error correction

\begin{tabular}{lll}
\hline \hline & MTAR & MTAR-consistent \\
\hline$\lambda^{+}$ & $-0.0036(-0.0285)$ & $-0.0227(-0.1962)$ \\
$\lambda^{-}$ & $-0.4386^{\mathrm{b}}(-2.2748)$ & $-0.4846^{\mathrm{b}}(-2.5897)$ \\
$R^{2}$ & 0.7677 & 0.7796 \\
Dw-statistic & 2.0396 & 2.1062 \\
B-G & $(0.8132)$ & $(0.5754)$ \\
B-P-G & $(0.9721)$ & $(0.3619)$ \\
J-B & $(1.3069)$ & $(1.4896)$ \\
F-statistics & $9.1804^{\mathrm{a}}$ & $9.8280^{\mathrm{a}}$ \\
\hline \hline
\end{tabular}

Notes: B-G: Breusch-Godfrey Serial Correlation LM Test, B-P-G: Heteroskedasticity Test by Breusch-Pagan-Godfrey, JB: Jargue-Bera test for normality, a denote significance at $1 \%$ level, b denote significance at $5 \%$ level.

\section{CONCLUSIONS}

The study employed annual statistical secondary data on GDP, real effective exchange rates, the consumer price index and oil prices. The empirical analysis examines the asymmetric effects of oil price changes on economic growth in Malaysia using annual data ranging from 1975 to 2015 by applying threshold autoregressive (TAR) and momentum threshold autoregressive (MTAR) cointegration and asymmetric adjustment models. The results revealed that the price of oil has an asymmetric impact on Malaysian economic growth. We found that increases in oil price accelerate the rate of economic growth and the speeds of adjustment back to the normal position were insignificant. Meanwhile a drop in oil prices tends to affect economic growth negatively and it returns back to its normal position. The results clearly showed that economic growth displayed 
asymmetric adjustments and were sensitive to oil price changes. This suggests that it is essential that policy makers consider different policy responses when oil prices change.

The results have important policy implications. The result implies that negative oil price shock would lower economic growth, however it is temporary. Therefore, policy makers might response by implementing expansionary monetary policy to stimulate economic growth. The explanation is intuitive. For example, an increase in the money supply would normally pull down the interest rate which would further encourage consumption and investment, stimulate economic growth, which would increase oil demand and push up its price. Even though the results revealed that Malaysian economic growth constantly benefits when the oil price increases and is temporarily negatively affected when oil price drop. This may suggest that the negative aspects of oil prices were absorbed by the non-oil counterpart. A decrease in oil price lowers the cost of production, hence increase productivity and economic growth. Since, our country benefited from diversified industries, government shall continue to encourage the expansion of various manufacturing, services and agriculture sectors.

\section{ACKNOWLEDGEMENTS}

The corresponding author would like to acknowledge the financial support by Universiti Putra Malaysia (UPM) under the Grant number: GP/2018/9632300.

\section{REFERENCES}

Aguiar-Conraria, L., \& Soares, M. J. (2011). Oil and the macroeconomy: Using wavelets to analyze old issues. Empirical Economics, 40(3), 645-655. https://doi.org/10.1007/s00181-010-0371$\mathrm{x}$

Ahmad, A. H., \& Aworinde, O. B. (2016). The role of structural breaks, nonlinearity and asymmetric adjustments in African bilateral real exchange rates. International Review of Economics \& Finance, 45, 144-159. https://doi.org/10.1016/j.iref.2016.05.004

Ahmad, A. H., \& Hernandez, R. M. (2013). Asymmetric adjustment between oil prices and exchange rates : Empirical evidence from major oil producers and consumers. Journal of International Financial Markets, Institutions \& Money, 27, 306-317. https://doi.org/10.1016/j.intfin.2013.10.002

Ahmed, H. J. A., \& Wadud, I. K. M. M. (2011). Role of oil price shocks on macroeconomic activities: An SVAR approach to the Malaysian economy and monetary responses. Energy Policy, 39(12), 8062-8069. https://doi.org/10.1016/j.enpol.2011.09.067

Aizenman, J., \& Pinto, B. (2004). Managing volatility and crises: A practitioner's guide overview. National Bureau of Economic Research., (No. w10602), 1-40. https://doi.org/10.3386/w10602

Aliyu, S. U. R. (2009). Impact of oil price shock and exchange rate volatility on economic growth in Nigeia: An empirical investigation. MPRA Working Paper No. 16319.

Aliyu, A. J., \& Tijjani, S. M. (2015). Asymmetric cointegration between exchange rate and trade balance in Nigeria. Cogent Economics \& Finance, 3(1), 1045213. https://doi.org/10.1080/23322039.2015.1045213 
Alley, I., Asekomeh, A., Mobolaji, H., \& Adeniran, Y. A. (2014). Oil price shocks and Nigerian economic growth. European Scientific Journal, 10(19), 375-391.

Baffes, J., Kose, M. A., Ohnsorge, F., \& Stocker, M. (2015). The great plunge in oil prices: Causes, consequences, and policy responses. World Bank Group, 1-51.

Bala, U., Songsiengchai, P., \& Chin, L. (2017). Asymmetric Behavior of Exchange Rate PassThrough in Thailand, Economics Bulletin, 37(2), 1289-1297.

Bala, U., \& Chin, L. (2018). Asymmetric impacts of oil price on inflation: An empirical study of African OPEC. Energies, 11(3017), 1-21. https://doi.org/10.3390/en11113017

Beechey, M., \& Osterholm, P. (2008). Revisiting the uncertain unit root in GDP and CPI: testing for non-linear trend reversion. Economic Letters, 100(2), 221-223.

Chang, H.-L., Su, C. W., Zhu, M.-N., \& Liu, P. (2010). Long-run purchasing power parity and asymmetric adjustment in BRICs. Applied Economics Letters, 17(11), 1083-1087. https://doi.org/10.1080/00036840902817458

Chang, T., Lu, Y.-C., Tang, D. P., \& Liu, W.-C. (2011). Long-run purchasing power parity with asymmetric adjustment: Evidence from African countries. Applied Economics, 43(2), 231242. https://doi.org/10.1002/ijfe.386

Chan, K. S. (1993). Consistency and limiting distribution of the least squares estimator of a Threshold Autoregressive Model, The Annals of Statistics, 21, 520-533.

Chen, J., Lee C., \& Goh, L. (2013). Exchange rate and oil price: asymmetric adjustment. Applied Economics Letters, 20(10), 987-990. https://doi.org/10.1080/13504851.2013.770118

Ekong, C. N., \& Effiong, E. L. (2015). Oil price shocks and Nigeria's macroeconomy: Disentangling the dynamics of crude oil market shocks. Global Economic Review, 16(6), 920-935. https://doi.org/10.1177/0972150915597594

Enders, W., \& Siklos, P. L. (2001). Cointegration and threshold adjustment. Journal of Business \& Economic Statistics, 19(2), 166-176. https://doi.org/10.1198/073500101316970395

Fattouh, B. (2010). The dynamics of crude oil price differentials. Energy Economics, 32(2), 334342. https://doi.org/10.1016/j.eneco.2009.06.007

Hooker, M. A. (2002). Are oil shocks inflationary? Asymmetric and nonlinear specifications versus changes in regime. Journal of Money, Credit and Banking, 34(2), 540-561. https://doi.org/10.1353/mcb.2002.0041

Ibrahim, M. H., \& Chancharoenchai, K. (2013). How inflationary are oil price hikes? A disaggregated look at Thailand using symmetric and asymmetric cointegration models. Journal of the Asia Pacific Economy, 19(3), 409-422. https://doi.org/10.1080/13547860.2013.820470

Izraf, M., Aziz, A., \& Dahalan, J. (2015). Oil price shocks and Macroeconomic activities in Asean5 countries: A panel VAR approach. Eurasian Journal of Business and Economics, 8(16), 101-120. https://doi.org/10.17015/ejbe.2015.016.06

Jammazi, R., Lahiani, A., \& Nguyen, D. K. (2015). A wavelet-based nonlinear ARDL model for assessing the exchange rate pass-through to crude oil prices. Journal of International Financial Markets, Institutions and Money, 34, 173-187.

Jbir, R., \& Zouari-Ghorbel, S. (2009). Recent oil price shock and Tunisian economy. Energy Policy, 37(3), 1041-1051. https://doi.org/10.1016/j.enpol.2008.10.044

Kriskkumar, K. \& Naseem, N. A. M. (2019). Analysis of oil price effect on economic growth of ASEAN net oil exporters, Energies, 12(17), 3343. https://doi.org/10.3390/en12173343

Lee, K., Ni, S., \& Ratti, R. A. (1995). Oil shocks and the macroeconomy: the role of price variability. Energy Journal, 16(4), 39-56. https://doi.org/10.5547/ISSN0195-6574-EJVol16-No4-2 
Liew, V. K., \& Balasubramaniam, A. (2017). Oil price shocks and sectoral outputs: Empirical evidence from Malaysia. Economic Bulletin, 37(1), 38-47.

Liu, J.-Y., Lin, S.-M., Xia, Y., Fan, Y., \& Wu, J. (2015). A financial CGE model analysis: Oil price shocks and monetary policy responses in China. Economic Modelling, 51, 534-543. https://doi.org/10.1016/j.econmod.2015.08.025

Madueme, S., \& Nwosu, O. C. (2010). Oil price shocks and macroeconomic variables in Nigeria. International Journal of Research in Arts and Social Sciences, 2, 333-342.

Mork, K. A., Olsen, O., \& Mysen, H. T. (1994). Macroeconomic responses to oil price increases and decreases in seven OECD countries. Energy Journal, 15(4), 19-35. http://doi.org/10.5547/ISSN0195-6574-EJ-Vol15-No4-2

Nazlioglu, S. (2011). World oil and agricultural commodity prices: Evidence from nonlinear causality. Energy Policy, 39(5), 2935-2943. http://doi.org/10.1016/j.enpol.2011.03.001

Noordin, N. S. (2009). Oil price shock and malaysian sectoral stock market return (Unpublished Masters Thesis). University of Malaya, Kuala Lumpur.

Olomola, P. A \& Adejumo, A. V. (2006). Oil price shock and macroeconomic activities in Nigeria. International Research Journal of Finance and Economics, 3(3), 28-34.

Pal, D., \& Mitra, S. K. (2015). Asymmetric impact of crude price on oil product pricing in the United States: An application of multiple threshold nonlinear autoregressive distributed lag model. Economic Modelling, 51, 436-443. http://doi.org/10.1016/j.econmod.2015.08.026

Puah, C. H., Liew, V. K. S. \& Tang, M. M. J. (2017). The pass-through effect of interest rate and asymmetric adjustment in Indonesia. Economic Annals XXI, 166(6-7), 61-66.

Rafiq, S., Salim, R., \& Bloch, H. (2009). Impact of crude oil price volatility on economic activities: An empirical investigation in the Thai economy. Resources Policy, 34(3), 121-132.

Rahman, S., \& Serletis, A. (2010). The asymmetric effects of oil price and monetary policy shocks: A nonlinear VAR approach. Energy Economics, 32(6), 1460-1466. http://doi.org/10.1016/j.eneco.2010.06.003

Razmi, F., Azali, M., Chin, L., \& Habibullah, M. S. (2016). The role of monetary transmission channels in transmitting oil price shocks to prices in ASEAN-4 countries during pre- and post-global financial crisis. Energy, 101, 581-591. https://doi.org/10.1016/j.energy.2016.02.036

Shelley, G. L., \& Wallace, F. H. (2011). Further evidents regarding nonlinear trend reversion of real GDP and the CPI. Economic Letters, 112(1), 56-59.

Wan, S. D., \& Lee, O. (2001). Tests for asymmetry in possibly nonstationary time series data. Journal of Business \& Economic Statistics, 19(2), 233-244.

Wong, K. K. S., \& Shamsudin, M. N. (2017). Impact of crude oil price, exchange rates and real GDP on Malaysia's food price fluctuations: Symmetric or asymmetric? International Journal of Economics and Management, 11(May), 259-275.

Xuan, P. P., \& Chin, L. (2015). Pass-through Effect of Oil Price into Consumer Price: An Empirical Study. International Journal of Economics and Management, 9(S), 143-161.

Xuan, P. P., Chin, L., \& Ismail, N. W. (2018). Energy consumption and real GDP nexus: a Malaysian case demonstrating the importance of trade openness. International Journal of Business and Society, 19(2), 449-463. 